\title{
Health of the Nation Outcome Scales for Infants field trial: concurrent validity
}

Peter Brann, Gordana Culjak, Nick Kowalenko, Rosemary Dickson, Tim Coombs, Philip Burgess, Anne Sved Williams, Elisabeth Hoehn and Margaret Hoyland

\section{Background}

A review of Australian mental health services identified a gap in routine outcome measures addressing social, emotional and behavioural domains for pre-schoolers and infants. A Child and Adolescent Mental Health Information Development Expert Advisory Panel working group developed the Health of the Nation Outcome Scales for Infants (HONOSI), a clinician-reported routine outcome measure for infants $0-47$ months. Prior face validity testing showed that the HoNOSI was considered useful in measuring mental health outcomes.

\section{Aims \\ To examine the concurrent validity of the HoNOSI.}

\section{Method}

Mental health clinicians providing assessment and treatment to infants in routine clinical practice participated in the study. The mental health status of 108 infants were rated by a minimum of 26 clinicians with the HoNOSI, the Parent-Infant Relationship Global Assessment Scale (PIR-GAS) and measures of symptom severity and distress.

\section{Results}

The HoNOSI was statistically significantly correlated with the PIR-;GAS, $r_{s}=-0.73$; Clinical Worry, $r_{s}=0.77$; and Severity
Judgement ratings, $r_{s}=0.85 ; P<0.001$. A good level of internal consistency was found. Using the Cosensus-based Standards for the selection of health Measurement INstruments (COSMIN) criteria for judging instrument acceptability, the HoNOSI meets the standard for both concurrent validity and internal consistency.

\section{Conclusions}

There has been a clear need for a routine outcome measure for use with infants. This study provides positive evidence of aspects of validity. These findings, along with those from the prior face validity study, support a controlled release of the HoNOSI accompanied by further research and development.

\section{Keywords}

HoNOSI; mental health; outcome measure; infants; validity.

\section{Copyright and usage}

(c) The Author(s), 2021. Published by Cambridge University Press on behalf of the Royal College of Psychiatrists. This is an Open Access article, distributed under the terms of the Creative Commons Attribution licence (http://creativecommons.org/ licenses/by/4.0/), which permits unrestricted re-use, distribution, and reproduction in any medium, provided the original work is properly cited.

\section{Background}

In 1990 Jenkins identified an urgent need for a system of indicators to enable clinicians to monitor and evaluate mental healthcare. ${ }^{1}$ One reason identified for not routinely using standard outcome measures was the lack of appropriate instruments. ${ }^{2}$

In 1998, Wing and colleagues ${ }^{3}$ developed the Health of the Nation Outcome Scales (HoNOS), an instrument covering symptoms, functioning, relationships and environmental issues ${ }^{4,5}$ that could be used routinely in the National Health Service (UK) to measure progress towards the target set by the Department of Health in the UK 'to improve significantly the health and social functioning of mentally ill people'. ${ }^{6}$ Since then, the HoNOS and its adaptations for children and adolescents (HoNOSCA) and for those over 65 years of age (HoNOS65+) have been officially adopted in England, Australia, New Zealand ${ }^{7}$ and in other European countries. ${ }^{8-10}$

\section{HONOSCA}

Gowers et $\mathrm{al}^{11}$ developed the HoNOSCA, for children and adolescents, as a set of scales to be used in child and adolescent mental health services. ${ }^{12}$ The HoNOSCA has been widely used. ${ }^{4,13-19}$ It was designed to be brief, have a similar structure to the HoNOS and provide a broad, quantitative measure of severity, with sound psychometric properties, to measure a range of behavioural, symptomatic, social and impairment domains in children and adolescents. ${ }^{1,20}$ HoNOSCA is most appropriately applied to those over 4 years old. ${ }^{21}$

\section{Developing the HoNOSI}

In Australia, the National Outcomes and Casemix Collection (NOCC) was introduced in the early 2000s 'to provide a suite of measures that support clinical practice and comparisons across services and different consumer populations'. ${ }^{19}$ The Strategic Directions 2014-2024 report $^{22}$ on the NOCC implementation and its future direction identified a gap in outcome measures for infants and pre-schoolers. The Australian Child and Adolescent Mental Health Information Development Expert Advisory Panel (CAMHIDEAP) provides advice on routine outcome measures and on information initiatives to the states, territories and the Commonwealth Government. ${ }^{23}$ CAMHIDEAP developed the Health of the Nation Outcome Scales for Infants (HoNOSI) ${ }^{24}$ as a routine outcome measure for clinicians working with the emotional and social well-being of children in the 0 - to 47 -month age group.

The HoNOSI arose out of an international collaboration around the reliability of the HoNOSCA. ${ }^{13}$ CAMHIDEAP decided the HoNOSI would parallel the structure of the HoNOSCA. A similar approach to ratings, number of scales, time frames and sources of information was considered to facilitate acceptance by clinicians who may work with both instruments. It could reduce training time. A key strategic consideration was that the adoption of a new outcome measure (especially across a nation) involves substantial financial costs associated with database development and maintenance. A similar structure would only require the addition of a 'version' flag, a relatively inexpensive approach, in order for HoNOSI ratings to be recorded and extracted from the existing HoNOSCA data space. 
The content of the 15 scales was initially developed by Dr Sally Merry of New Zealand, with in principle support from key figures of the HoNOSCA reliability collaboration from the UK, Denmark, Norway and Australia. Dr Merry, with support from infant and child mental health colleagues, either paralleled HoNOSCA scales where appropriate, or replaced them with more developmentally appropriate areas of concern. Continuity of outcomes could be assisted by maintaining both structural similarity and maximising content overlap where appropriate.

Face validity testing ${ }^{25}$ showed that the HoNOSI fulfilled a much-needed gap in infant mental health outcome measurement for the 0 - to 47 -month age group as no suitable instrument previously existed. Following face validity testing, the CAMHIDEAP working group identified the need for field testing to test selected psychometric properties of the HoNOSI.

\section{Aim}

The HoNOSI field trial was designed to examine concurrent validity how well HoNOSI ratings correlate with other measures of similar constructs.

\section{Method}

The CAMHIDEAP nominated key clinicians across a range of Australian states who were engaged in providing mental health services to infants and pre-schoolers. These key clinicians approached their own and allied services that provided infant mental health services. Many of these clinicians had previously been involved in the face validity study. ${ }^{25}$ Services from states previously participating in the face validity study were invited to participate from Queensland, New South Wales, Victoria and South Australia.

Concurrent validity was assessed with patients in routine clinical care by comparing clinician's ratings on the HoNOSI against the Parent-Infant Relationship Global Assessment Scale (PIRGAS), Clinical Worry Rating scale and Severity Judgement Rating scale (see Psychometric properties tested section below for further details). Each infant was rated by one clinician on each of these four measures. Data was collected from five participating services across four states. Participants were given an overview of the study, including rationale, background and aims and were provided with an information sheet that they were asked to read, before signing a consent form in order to be able to participate. Site coordinators emphasised that the clinician's information would remain confidential and be analysed in aggregate, anonymous form only. Copies of the study protocol were included with the study material for co-ordinators' and participants' reference.

Instructions for using the HoNOSI, PIR-GAS, Clinical Worry and Severity Judgement Rating scales were included with the instruments. Additional background material and principles for rating as well as the glossary for each scale were incorporated into the HoNOSI. Participants were encouraged to ask any questions of the site co-ordinator or the project co-ordinator.

Signed consent forms and completed ratings were returned via courier to the Health Education and Training Institute for data input and analysis. In the rare event that the clinician returned a completed rating scale(s) without having completed a consent form, consent was implied via the participant's return of the completed outcome rating. No information was sought from children, infants or parents. Ethics and site-specific approval were obtained from the respective Ethics and Research and Governance Offices within each participating state - New South Wales, Queensland, Victoria and South Australia.

\section{Psychometric properties tested}

The COnsensus based Standards for the selection of health Measurement INstruments (COSMIN) ${ }^{26}$ initiative was developed to provide guidance on the selection of high-quality patient-reported outcome measures to clinical and research applications. ${ }^{27}$ This includes providing a methodology for assessing the content validity of patientreported outcome measures. ${ }^{26,28}$ It comprises a taxonomy and definitions of measurement properties, ${ }^{29}$ checklists for assessing the methodological quality of measurement properties ${ }^{30}$ and criteria for good measurement properties, against which to evaluate study results. ${ }^{27}$

The minimum 'acceptable' COSMIN standard for internal consistency, or the degree of interrelatedness among items, is $0.70 .^{27}$ The COSMIN standard for assessing concurrent validity, or the correlation of the measure of interest with a 'gold standard' is $0.70 .^{29}$ The 'gold standard' is another measure, or set of measures, that assesses a similar construct.

As no single gold standard measure of clinician-rated mental health symptoms and functioning existed at that time, ${ }^{31}$ the working group determined that the best comparison available was to test $\mathrm{HoNOSI}^{24}$ against the Parent-Infant Relationship Global Assessment Scale, ${ }^{32}$ widely used in Germany, ${ }^{33,34}$ Denmark, ${ }^{35}$ the USA $^{32,36}$ and Australia. ${ }^{37}$ As HoNOSI also covers symptom severity and perceived distress as well as functioning, two simple scales, developed by the project working group (Clinical Worry and Severity Judgement) ${ }^{31}$ were also rated.

\section{Measures}

The HoNOSI ${ }^{24}$ contains 15 single-item scales that address a range of symptoms and functioning that can occur in the infant-to-preschool age range (see Appendix). Each scale is accompanied by a glossary outlining the range of issues covered and is rated on a $0-4$-point scale ranging from 'No problem' to 'Severe problem'. The guidelines allow clinicians to include all sources of information when making a rating and do not simply presume that any difficulty is located exclusively within the infant. In parallel with the HoNOSCA, the first 13 scales cover clinical areas and are summed to form a total score. Missing data is treated as zero in calculating totals. Scales 14 and 15 focus on information about the situation $^{38}$ and do not contribute to the total score.

Clinicians' ratings on the HoNOS family of measures can be categorised as 'clinically significant' if a problem area is rated as mild, moderate or severe to very severe problem (i.e. a rating of 2 , 3 or 4 ) or 'clinically not significant' for ratings of 0 or $1 .{ }^{39}$ Full details on study procedures and HoNOSI scoring instructions are available in the HoNOSI field trial report. ${ }^{31}$

The PIR-GAS ${ }^{32}$ is a measure of the quality of the parent-infant relationship. ${ }^{32}$ Clinicians assess the intensity, frequency and duration of difficulties on a 100-point rating scale, usually reported in deciles, that ranges from 1-10 Documented Maltreatment to 91100 Well Adapted.

The Clinical Worry Rating, ${ }^{31}$ a seven-point rating scale, developed by the HoNOSI project working group, asks the clinician to rate: 'Overall, how concerned are you about this infant?'. The Severity Judgement Rating, ${ }^{31}$ also a seven-point rating scale developed by the working group, asks the clinician to rate: 'In your clinical judgement, how severe do you consider the infant's overall social and emotional problems?'. Both the Clinical Worry Rating and the Severity Judgement Rating scales were designed to be unidirectional, from 0 (Not worried/No problem) to 6 (Extreme/Severe).

Based on the directionality of the measures, the previously discussed COSMIN standards indicate that adequate concurrent validity would be achieved if the HoNOSI had a statistically significant correlation of at most negative 0.70 with PIR-GAS and at least 0.70 with the Clinical Worry and the Severity Judgement Rating scales. 
Table 1 Infants rated by clinician's profession type

\begin{tabular}{lcccrr|} 
& \multicolumn{2}{c}{ Clinicians } & & \multicolumn{2}{c}{ Infants } \\
\cline { 2 - 3 } \cline { 5 - 6 } Profession & $n$ & $\%$ & & $n$ & $\%$ \\
Psychologist & 8 & 30.8 & & 41 & 38.0 \\
Social worker & 6 & 23.1 & & 30 & 27.8 \\
Psychiatrist & 4 & 15.4 & 10 & 9.3 \\
Nurse & 3 & 11.5 & & 15 & 13.9 \\
Occupational therapist & 1 & 3.8 & 7 & 6.5 \\
Speech pathologist & 1 & 3.8 & & 0.9 \\
Unknown & 3 & 11.5 & & 4 & 3.7 \\
Total & 26 & 100.0 & & 108 & 100.0 \\
\hline
\end{tabular}

\section{Table 2 Infants rated by clinicians' years of experience}

\begin{tabular}{lrrrrr} 
& \multicolumn{2}{c}{ Clinicians } & & \multicolumn{2}{c}{ Infants } \\
\cline { 2 - 3 } Clinical experience & $n$ & $\%$ & & $n$ & $\%$ \\
<2 years & 5 & 19.2 & 15 & 13.9 \\
2-5 years & 4 & 15.4 & 9 & 8.3 \\
5-10 years & 10 & 38.5 & 47 & 43.5 \\
10+ years & 6 & 23.1 & 35 & 32.4 \\
Unknown & 1 & 3.8 & 2 & 1.9 \\
Total & 26 & 100.0 & 108 & 100.0 \\
\hline
\end{tabular}

\section{Data collection and analysis}

Data was collected from five participating services within four states across Australia. The analysis dataset consisted of 108 completed clinical cases. A HoNOSI 'item severity structure' index was derived using the method described by Gowers et al (1999) ${ }^{11}$ with respect to the HoNOSCA. Statistical analyses were performed using SPSS Version $24^{40}$ and Stata Version 14.2. ${ }^{41}$

\section{Results}

Using a combination of jurisdiction, profession and years' experience, it is estimated that 26 clinicians participated. The number of infants rated varied from 1 to 14 with a mode of 3.5. The number of infants rated across the five sites ranged from 6 to 55 with two services being responsible for $78 \%$ of the infants rated. All statistical analyses used a type error rate of $\alpha<0.05$ and their associated probability are reported.

\section{Profession characteristics}

Over half of the clinicians were either psychologists or social workers and these two professions completed approximately twothirds of all ratings. Table 1 shows the estimated number of clinicians and the number of ratings completed by profession type.

\section{Clinical experience}

Over $61 \%$ of clinicians rating the cases had over 5 years' experience and of those, $23 \%$ had clinical experience of over 10 years; these clinicians rated more than $75 \%$ of the cases. Table 2 shows the estimated
Table 4 Distribution of Parent-Infant Relationship Global Assessment Scale (PIR-GAS) ratings $(n=104)$

\section{PIR-GAS Ratings for clinical cases}

1-10 Documented Maltreatment

11-20 Grossly Impaired

21-30 Severely Disordered

31-40 Disordered

41-50 Disturbed

51-60 Distressed

61-70 Significantly Perturbed

71-80 Perturbed

81-90 Adapted

91-100 Well Adapted

Total $^{\mathrm{a}}$

$\%$
0.0
1.0
11.5
29.8
15.4
16.3
8.7
8.7
5.8
2.9
00.0

\section{There were four non-responses to the PIR-GAS}

\begin{tabular}{lrlr}
$\begin{array}{l}\text { Table } \mathbf{5} \\
(n=108)\end{array}$ & Distribution of Clinical Worry and Severity Judgement ratings \\
\hline Ratings & $\%$ & Ratings & $\%$ \\
Clinical Worry & & Severity Judgement \\
Not concerned - 0 & 10.2 & No Problem - 0 & \\
1 & 9.3 & 1 & 15.7 \\
2 & 12.0 & 2 & 11.1 \\
3 & 26.9 & 3 & 16.7 \\
4 & 24.1 & 4 & 23.2 \\
5 & 12.0 & 5 & 20.4 \\
Extremely concerned - 6 & 5.6 & Extremely severe problem -6 & 8.3 \\
Total & 100.0 & Total & 100.0 \\
& & &
\end{tabular}

number of clinicians and the number of ratings completed by the clinicians' years of experience.

\section{Infant characteristics}

Basic demographic data were collected regarding the age and gender of the infant. There were slightly more male $(52.8 \%)$ than female infants (47.2\%). The age distributions differed; male infants were somewhat older than female infants, with median ages of 16 and 10 months, respectively. Table 3 shows the age distribution of the infants.

On PIR-GAS, some infants were classified as Adapted Relationship but most had Features of a Disordered Relationship (PIR-GAS rating 41-80; 49.1\%) or a Disordered Relationship (PIR-GAS rating $1-40 ; 42.3 \%){ }^{32}$ Table 4 shows the distribution of PIR-GAS ratings.

The majority of infants were rated as either a ' 3 ' or a ' 4 ' in terms of Clinical Worry (51.0\%) and Severity Judgement (43.6\%) on their respective seven-point rating scales, where zero denotes Not Concerned and No Problem and a score of six denotes Extremely Concerned and Extremely Severe Problem on the Clinical Worry and Severity Judgement Rating scales, respectively (Table 5).

\section{Distribution of HoNOSI ratings}

The frequency distribution of severity ratings for each of the 15 HoNOSI scales is presented in Fig. 1.

\begin{tabular}{|c|c|c|c|c|c|c|c|c|c|c|}
\hline \multirow[b]{2}{*}{ Gender } & \multirow[b]{2}{*}{$n$} & \multirow[b]{2}{*}{ Mean } & \multirow[b]{2}{*}{ s.d. } & \multirow[b]{2}{*}{ Minimum } & \multirow[b]{2}{*}{ Maximum } & \multicolumn{5}{|c|}{ Percentile } \\
\hline & & & & & & 10th & 25th & 50th & 75th & 90th \\
\hline Male & 57 & 18.3 & 14.0 & 1 & 47 & 3 & 5 & 16 & 30 & 38 \\
\hline Female & 51 & 16.3 & 13.9 & 1 & 47 & 2 & 5 & 10 & 25 & 41 \\
\hline Total & 108 & 17.3 & 14.0 & 1 & 47 & 2 & 5 & 15 & 26 & 41 \\
\hline
\end{tabular}




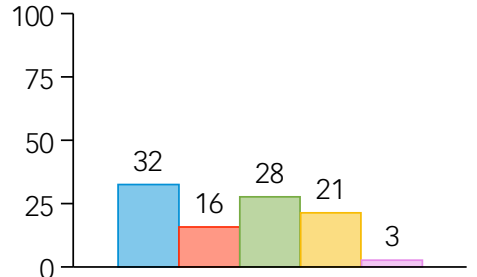

01: Disruptive, Cases

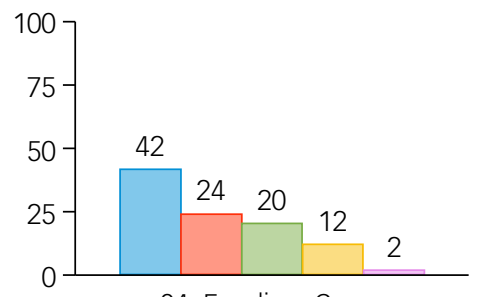

04: Feeding, Cases

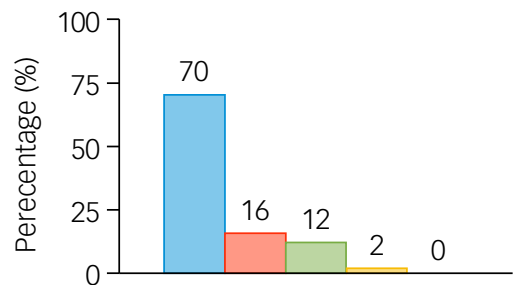

07: Sensory, Cases

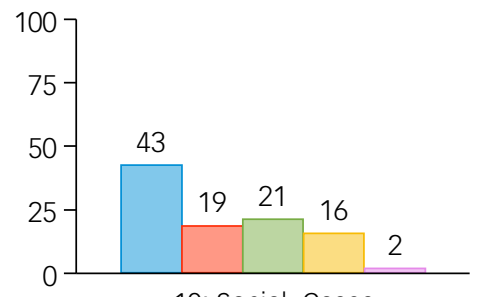

10: Social, Cases

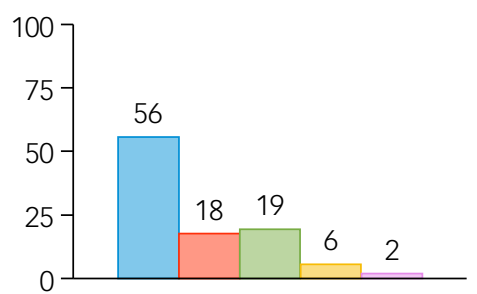

13: Care settings, Cases

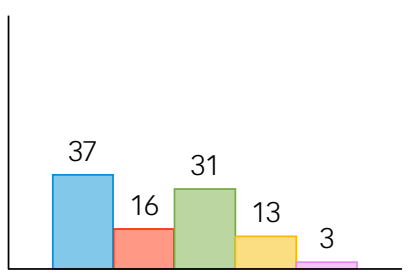

02: Activity, Cases

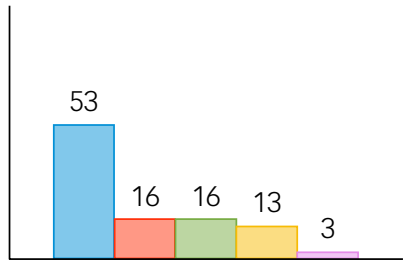

05: Development, Cases

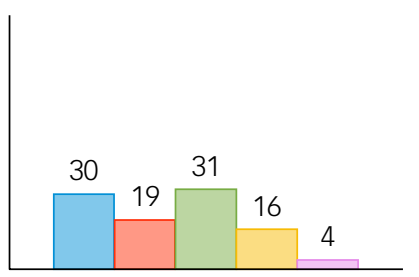

08: Sleep, Cases

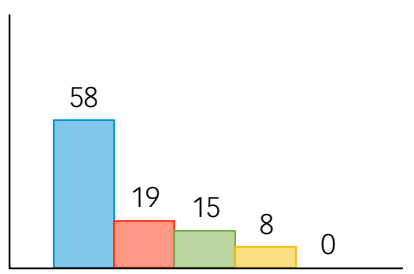

11: Self-care, Cases

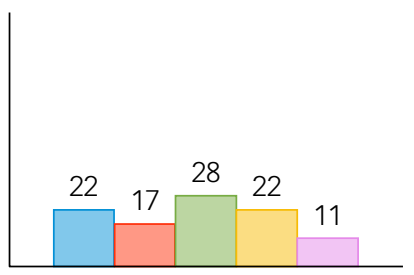

14: Knowledge, Cases

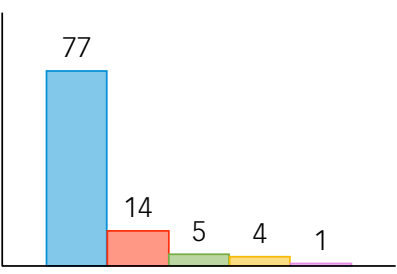

03: Self-injury, Cases

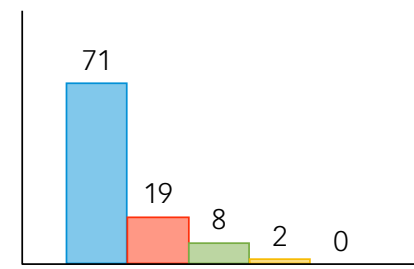

06: Physical, Cases

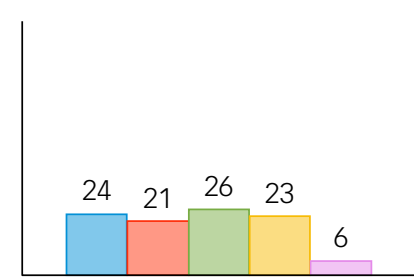

09: Emotional, Cases

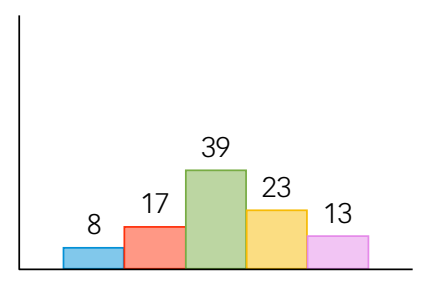

12: Family, Cases

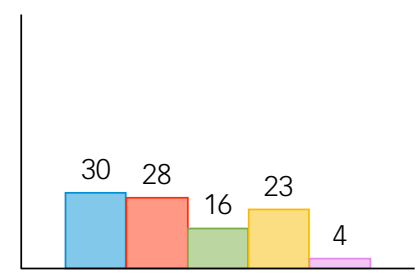

15: Information, Cases

\section{Fig. 1 Ratings for the 15 Health of the Nation Outcome Scales for Infants (HONOSI).}

There were no missing HoNOSI ratings and no infants received a rating of Not known/Not applicable. Of the 108 cases, all five rating points were used for 12 of the 15 HoNOSI scales; the most severe rating of four was not used for Scale 6 Problems with physical illness or disability, Scale 7 Problems associated with regulation and integration of sensory processing and Scale 11 Problems with age appropriate self-care and environmental exploration. For six scales, over half of all ratings were rated zero indicating 'No problems/Issues' (Scale 3 Non-accidental self-injury or lack of self-protective behaviours, Scale 5 Problems with developmental delays,
Scale 6 Problems with physical illness or disability, Scale 7 Problems associated with regulation and integration of sensory processing, Scale 11 Problems with age appropriate self-care and environmental exploration and Scale 13 Problems with attending care, education and socialisation settings).

Using the HoNOS family of measures classification where a rating of 2, 3 or 4 is classified as clinically significant, with respect to the 108 cases, $75 \%$ were rated as having clinically significant problems with Scale 12 Problems with family life and relationships, 55\% with Scale 9 Problems with emotional and related symptoms or over-controlled 


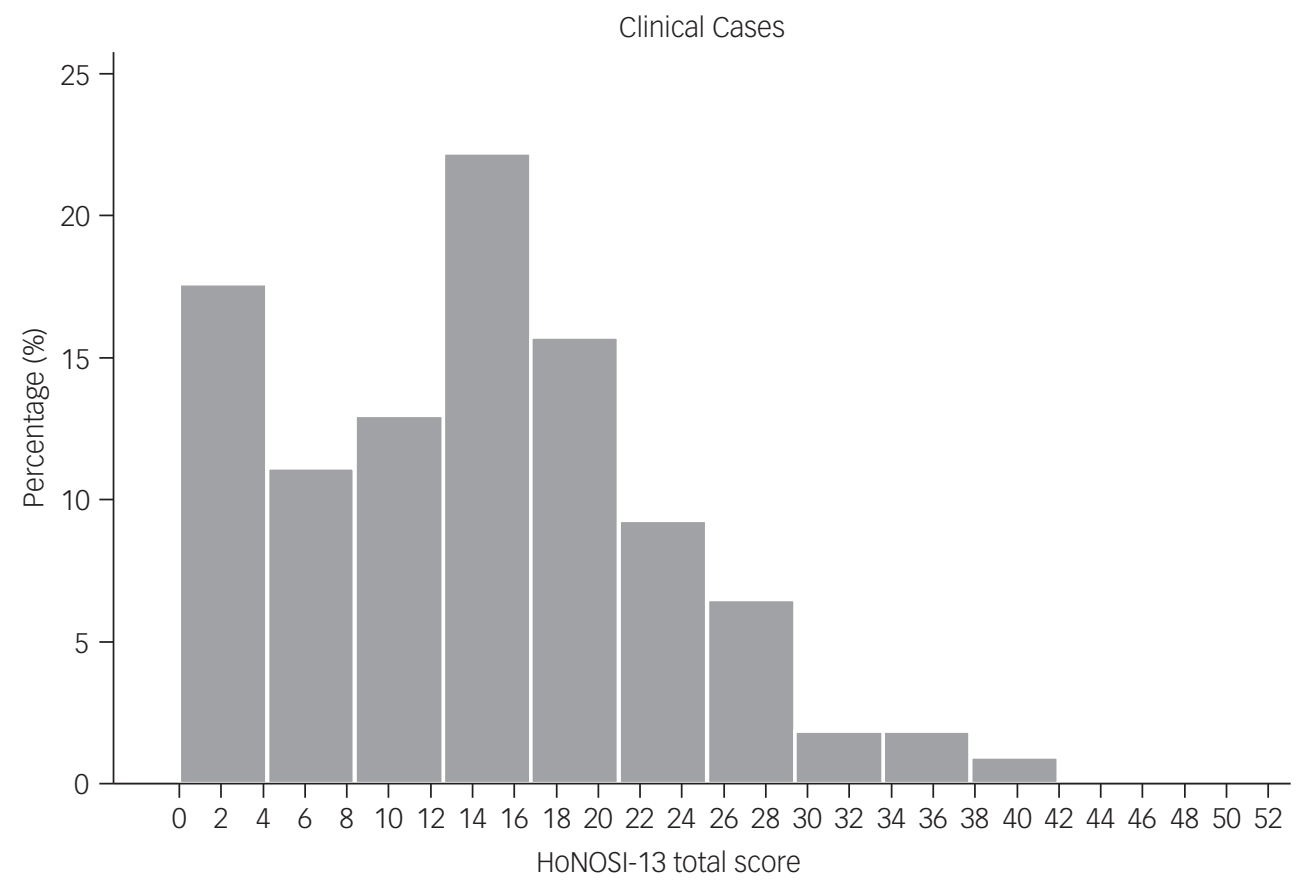

Fig. 2 Distribution of Health of the Nation Outcome Scales for Infants (HONOSI) total scores.

emotional regulation, $52 \%$ with Scale 1 Problems with disruptive behaviour/irritability/under controlled emotional regulation and 51\% with Scale 8 Problems associated with sleep. The scales least frequently rated as clinically significant were Scale 3 Non-accidental self-injury or lack of self-protective behaviours (10\%), Scale 6 Problems with physical illness or disability (10\%) and Scale 7 Problems associated with regulation and integration of sensory processing (14\%).

Clinically significant problems were also found for $61 \%$ on Scale 14 Problems with knowledge or understanding about the nature of the infant's difficulties and for $43 \%$ on Scale 15 Problems with lack of information, understanding about services, or managing the infant's difficulties.

Figure 2 presents the distribution of HoNOSI total scores (sum of the ratings of the first 13 scales). HoNOSI total scores ranged from 0 through 42 , with a mean and median of 14.0 and an interquartilerange of 12 points (i.e. the middle $50 \%$ of total scores were within the range 7 through 19) (Table 6). Analysis of the distribution of the total scores did not reveal any significant deviation from normality.

Collins et al (2016) address floor and ceiling effects for measures reporting total scores as 'the percentage of respondents with the lowest possible score (floor effects) and the highest possible score (ceiling effects)'. ${ }^{42}$ Floor and ceiling effects are not considered statistically significant if less than $15 \%$ of participants score the lowest or the highest possible score. There was no evidence of these effects in the HoNOSI total scores (Fig. 2). Only six cases (5.6\%) had a HoNOSI total score of zero and only one case had a HoNOSI total score of $42(0.9 \%)$.

In terms of item severity structure, it is important to note that more than $80 \%$ of cases had at least one HoNOSI scale problem area rated as clinically significant. Table 7 shows details on the item severity structure index by the mean HoNOSI total score.

Spearman's rank order correlation was used to test the concurrent validity of the HoNOSI total score with the PIR-GAS, Clinical Worry and Severity Judgement Rating scales and the results are presented in Table 8. A comprehensive intercorrelation analysis of the 15 individual HoNOSI scales is available in Supplementary Table 1 available at https://doi.org/10.1192/bjo.2021.951. It shows that that all 15 HoNOSI scale correlations with the PIR-GAS, Clinical Worry and Severity Judgement Ratings are statistically significant $(P<0.001)$ with the one exception of Scale 6 correlated against the Clinical Worry Rating, which is also statistically significant at a lower threshold $(P<0.05)$. The HoNOSI total score correlations summary table (Table 8 ) shows the three validity measures correlated against the HoNOSI total score. It is also important to note that the three concurrent validity measures are highly statistically intercorrelated $(P<0.001)$ : PIR-GAS with Clinical Worry, $r_{s}=-0.81$; PIR-GAS with Severity Judgement, $r_{s}=-0.76$; and Clinical Worry with Severity Judgement, $r_{s}=0.81$.

\section{Discussion}

\section{Main findings}

This study was designed specifically to establish the level of evidence of concurrent validity with respect to the 15 HoNOSI scales and the HoNOSI total severity score. In order to test concurrent validity, in the absence of a gold standard, the HoNOSI was compared with

Table 6 Distribution of Health of the Nation Outcome Scales for Infants (HONOSI) total score in clinical cases $(n=108)$

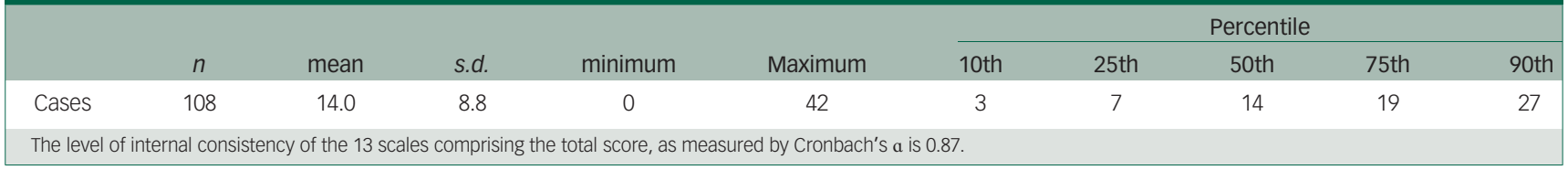


Table 7 Health of the Nation Outcome Scales for Infants (HONOSI) item severity structure by HONOSI total score $(n=108)$

\begin{tabular}{lrrcc} 
HoNOSI Severity Index & \multicolumn{1}{c}{$\begin{array}{c}\text { Cumulative } \\
\%\end{array}$} & $\begin{array}{c}\text { HoNOSI } \\
\text { (mean) }\end{array}$ \\
Two or more ratings of 4 & 9 & 8.3 & 8.3 & 27.0 \\
Only one rating of 4 & 12 & 11.1 & 19.4 & 17.7 \\
No 4 ratings, any ratings of 3 & 42 & 38.9 & 58.3 & 17.4 \\
No 3 or 4 ratings, any ratings of 2 & 28 & 25.9 & 84.2 & 10.0 \\
No 2-4 ratings, any ratings of 1 & 11 & 10.2 & 94.4 & 4.1 \\
O ratings only & 6 & 5.6 & 100 & 0 \\
Total & 108 & 100 & 100 & 14.0 \\
& & & &
\end{tabular}

Table 8 Correlation of Health of the Nation Outcome Scales for Infants (HoNOSI) total score with Parent-Infant Relationship Global Assessment Scale (PIR-GAS), Clinical Worry and Severity Judgement rating scales

\begin{tabular}{|lcccc|}
\hline & \multicolumn{4}{c|}{ Spearman's rho correlation coefficient ${ }^{\text {a }}$} \\
\cline { 2 - 5 } & $\begin{array}{c}\text { PIR-GAS } \\
(n=104)\end{array}$ & $\begin{array}{c}\text { Clinical } \\
(n=108)\end{array}$ & $\begin{array}{c}\text { Severity } \\
\text { Judgement } \\
(n=108)\end{array}$ & $\begin{array}{c}\text { HoNOSI } \\
\text { total score } \\
(n=108)\end{array}$ \\
\hline PIR-GAS & 1.00 & & & \\
Clinical Worry & -0.81 & 1.00 & 1.00 & 1.00 \\
Severity Judgement & -0.76 & 0.81 & 0.85 & \\
HoNOSI Total Score & -0.73 & 0.77 & \\
\hline a. All correlations were statistically significant $(P<0.001)$. & \\
\hline
\end{tabular}

other measures that measure similar constructs: the PIR-GAS, Clinical Worry and Severity Judgement Rating scales.

The level of internal consistency of the 13 scales comprising the total score, as measured by Cronbach's a, is 0.87 which well exceeds the COSMIN threshold. It should also be noted that the evaluation of the concurrent validity of HoNOSI was based on three independent measures. The three concurrent validity measures are highly statistically intercorrelated, suggesting a high degree of construct congruence. Using the COSMIN criteria, there is evidence for HoNOSI having 'adequate' concurrent validity, as assessed by correlations with the PIR-GAS, Clinical Worry and Severity Judgement Rating scales.

More than $80 \%$ of cases had at least one HoNOSI scale problem area rated as clinically significant. This finding suggests that the overall clinical severity of these 108 cases is likely representative of very young consumers seen in specialised public sector mental health services. This was not a sample that was symptom free.

Examining ratings of individual scales, no infants received a rating of Not known, nor were there any missing ratings. This suggests that all 15 scales were able to be used. The most severe rating of 4 was not used for three of the 15 scales: Scale 6 Problems with physical illness or disability, Scale 7 Problems associated with regulation and integration of sensory processing and Scale 11 Problems with age appropriate self-care and environmental exploration. It could be in this sample of 108 infants, that there were no cases with Severe to very severe problem for the HoNOSI problem areas. Alternatively, it could be that the glossary for these scales means that it is unlikely that a rating of 4 would be used. Future work could further explore these particular scales in another sample.

\section{Future research}

Future research could also explore HoNOSI validity with respect to other domains and consumer attributes including the specific nature of presenting problems and diagnostic categories. There was relatively brief written training, embedded in HoNOSI, provided in this study. Although this brief approach may be seen to mirror what clinicians receive in real-world settings post any initial implementation, ${ }^{43}$ the impact of additional training on the performance of HoNOSI would be worth exploring. With the adult routine outcome measure, the type of training required, and its capacity to improve psychometric, and clinician, performance is an area of longstanding debate. ${ }^{44,45}$

There are other psychometric properties (for example, sensitivity to change) yet to be investigated. A face validity study, ${ }^{25}$ an interrater reliability study ${ }^{46}$ and this concurrent validity field trial have now been completed. The findings have been sufficiently encouraging to support controlled implementation of the HoNOSI.

Peter Brann (DD, Eastern Health Child Youth Mental Health Service and Adjunct Lecturer Monash University, Australia; Gordana Culjak (D), Australian Mental Health Outcomes and Classification Network (AMHOCN), Sydney, Australia; and Health Education and Training Institute (HETI), Sydney Medical School, University of Sydney, Australia; Nick Kowalenko (D), Department of Psychological Medicine, Saunders Unit - Mental Health, Children's Hospital Randwick, Sydney Children's Hospital Network, Australia; and Sydney Medical School, University of Sydney, Australia; Rosemary Dickson, Child and Adolescent Mental Health Information Development Expert Advisory Panel (CAMHIDEAP) Secretariat, Australian Mental Health Outcomes and Classification Network (AMHOCN), Health Education and Training Institute (HETI), Australia; Tim Coombs $\mathbb{D}$, Australian Mental Health Outcomes and Classification Network (AMHOCN), Sydney, Australia; and Mental Health Outcomes and Classification Network (AMH Philip Burgess Sydney, Australia; and School of Public Health, Faculty of Medicine, The University of Queensland, Australia; Anne Sved Williams $\mathbb{B}$. University of Adelaide and Consultant Psychiatrist, Women's and Children's Health Network, Australia; Elisabeth Hoehn (D), Queensland Centre for Perinatal and Infant Mental Health Child and Youth Mental Health Service (CYMHS), Children's Health Queensland Hospital and Health Service, Australia; Margaret Hoyland (10, Child and Youth Mental Health Service (CYMHS), Children's Health Queensland Hospital and Health Service, Australia

Correspondence: Gordana Culjak. Email: gordana.culjak@uni.sydney.edu.au First received 25 May 2020, final revision 28 May 2021, accepted 29 May 2021

\section{Supplementary material}

Supplementary material is available online at https://doi.org/10.1192/bjo.2021.951.

\section{Funding}

The study was undertaken by the Child and Adolescent Mental Health Information Development Expert Advisory Panel (CAMHIDEAP), supported by the Australian Mental Health Outcomes and Classification Network (AMHOCN). CAMHIDEAP and AMHOCN have been funded by the Australian Government Department of Health through a contract with the Health Education and Training Institute.

\section{Data availability}

The data that support the findings of this study are available from the corresponding author (G.C.) upon reasonable request.

\section{Author contributions}

All authors contributed to the conception and design of the study. G.C. conducted the field trial, initial analysis, interpretation of data and wrote the draft manuscript. G.C. and P.B. conducted the final analysis and prepared the final manuscript. All authors reviewed and approved the final version of the manuscript.

\section{Declaration of interest}

None.

\section{Appendix}

Health of the Nation Outcome Scales for Infants

$\begin{array}{ll}\text { Scale } & \text { Description } \\ 1 & \begin{array}{c}\text { Problems with disruptive behaviour/irritability/under controlled } \\ \text { emotional regulation }\end{array} \\ 2 & \begin{array}{l}\text { Problems with activity levels, joint and/or sustained attention } \\ 3\end{array} \\ 4 & \text { Non-accidental self-injury or lack of self-protective behaviours } \\ 5 & \text { Problems with feeding and eating behaviour } \\ 6 & \text { Problems with developmental delays }\end{array}$

(Continued) 


\begin{tabular}{|c|c|}
\hline Scale & Description \\
\hline 7 & $\begin{array}{l}\text { Problems associated with regulation and integration of sensory } \\
\text { processing }\end{array}$ \\
\hline 8 & Problems associated with sleep \\
\hline 9 & $\begin{array}{l}\text { Problems with emotional and related symptoms or over-controlled } \\
\qquad \text { emotional regulation }\end{array}$ \\
\hline 10 & Problems with social reciprocity \\
\hline 11 & $\begin{array}{l}\text { Problems with age appropriate self-care and environmental } \\
\text { exploration }\end{array}$ \\
\hline 12 & Problems with family life and relationships \\
\hline 13 & Problems with attending care, education and socialisation settings \\
\hline 14 & $\begin{array}{l}\text { Problems with knowledge or understanding about the nature of the } \\
\text { infant's difficulties }\end{array}$ \\
\hline 15 & $\begin{array}{c}\text { Problems with lack of information, understanding about services, } \\
\text { or managing the infant's difficulties }\end{array}$ \\
\hline
\end{tabular}

\section{References}

1 Jenkins R. Towards a system of outcome indicators for mental health care. Br J Psychiatry 1990; 157: 500-14.

2 Slade M, Thornicroft G, Glover G. The feasibility of routine outcome measures in mental health. Soc Psychiatry Psychiatr Epidemiol 1999; 34: 243-9.

3 Wing JK, Beevor AS, Curtis RH, Park SGB, Hadden J, Burns A. Health of the Nation Outcome Scales (HoNOS): Research and development. Br J Psychiatry 1998; 172: 11-8.

4 Laugharne R, Eaves S, Mascas A, Psatha K, Dinnis G, Trower J, et al. Desperately seeking outcomes: quantifying the effectiveness of community mental healthcare using Health of the Nation Outcome Scales. BJPsych Open 2018; 4: 91-4.

5 Kisely S, Campbell LA, Cartwright J, Cox M, Campbell J. Do the Health of the Nation Outcome Scales measure outcome? Can J Psychiatry 2010; 55: 431-9.

6 Department of Health. Health of the Nation. White Paper. HMSO, 1992.

7 James M, Painter J, Buckingham B, Stewart MW. A review and update of the Health of the Nation Outcome Scales (HoNOS). BJPsych Bull 2018; 42: 63-8.

8 Lovaglio PG, Monzani E. Validation aspects of the Health of the Nation Outcome Scales. Int J Ment Health Syst 2011; 5: 20.

9 Adamis D, Papanikolaou V, Michailidis M, Macdonald AJ. Validation of the Greek version of the Health of the Nation Outcome Scales for Elderly People (HoNOS65+, version 3). Aging Ment Health 2013; 17: 258-64.

10 Bilenberg $\mathrm{N}$. Health of the Nation Outcome Scales for Children and Adolescents (HoNOSCA)-results of a Danish field trial. Eur Child Adolesc Psychiatry 2003; 12: 298-302.

11 Gowers SG, Harrington RC, Whitton A, Lelliott P, Beevor A, Wing J, et al. Brief scale for measuring the outcomes of emotional and behavioural disorders in children. Health of the Nation Outcome Scales for Children and Adolescents (HoNOSCA). Br J Psychiatry 1999; 174: 413-6.

12 Gowers SG, Bailey-Rogers SJ, Shore A, Levione W. The Health of the Nation Outcome Scales for Child and Adolescent Mental Health (HoNOSCA). Child Psychol Psychiatry Rev 2000; 5: 50-6.

13 Hanssen-Bauer K, Gowers S, Aalen OO, Bilenberg N, Brann P, Garralda E, et al. Cross-national reliability of clinician-rated outcome measures in child and adolescent mental health services. Adm Policy Ment Health 2007; 34: 513-8.

14 Trauer T. Outcome Measurement in Mental Health: Theory and Practice. Cambridge University Press, 2010.

15 Pirkis JE, Burgess PM, Kirk PK, Dodson S, Coombs TJ, Williamson MK. A review of the psychometric properties of the Health of the Nation Outcome Scales (HoNOS) family of measures. Health Qual Life Outcomes 2005; 3: 76.

16 Brann $P$, Coleman $G$. On the meaning of change in a clinician's routine measure of outcome: HoNOSCA. Aust N Z J Psychiatry 2010; 44: 1097-4.

17 Duffy F, Skeldon J. A CAMHS Intensive Treatment Service: clinical outcomes in the first year. Clin Child Psychol Psychiatry 2014; 19: 90-9.

18 Lesinskiene S, Senina J, Ranceva N. Use of the HoNOSCA scale in the teamwork of inpatient child psychiatry unit. J PSychiatr Ment Health Nurs 2007; 14: 727-33.

19 Brann $\mathrm{P}$, Alexander $\mathrm{M}$, Coombs T. Routine outcome measurement in youth mental health: a comparison of two clinician rated measures, HoNOSCA and HoNOS. Psychiatry Res 2012; 200: 884-9.

20 Australian Mental Health Outcomes and Classification Network 'Sharing Information to Improve Outcomes'. An Australian Government funded initiative. Review of the Standardised Measures Used in the National Outcomes and Casemix Collection (NOCC). Commonwealth of Australia, 2005 (https:// www.amhocn.org/sites/default/files/publication_files/review_of_nocc_measures_ version_1.2.pdf).

21 Child Outcomes Research Consortium. Health of the Nation Outcome Scales for Children and Adolescents. The Kantor Centre of Excellence, 2021 (https:// www.corc.uk.net/outcome-experience-measures/health-of-the-nation-outcomescales-for-children-and-adolescents/).

22 National Mental Health Information Development Expert Advisory Panel. Mental Health National Outcomes and Casemix Collection: NOCC Strategic Directions 2014-2024. Commonwealth of Australia, 2013.

23 Australian Mental Health Outcomes and Classification Network. Child and Adolescent Mental Health Information Development Expert Advisory Panel CAMHIDEAP. Australian Mental Health Outcomes and Classification Network, 2020 (https://www.amhocn.org/expert-advisory-panels/child-and-adolescentmental-health-information-development-expert-advisory).

24 Commonwealth of Australia. HoNOSI Health of the Nation Outcome Scales for Infants (0-47 months). Glossary. Ver 0.93. Developed under the guidance of the Child and Adolescent Mental Health Information Development Expert Advisory Panel. Australian Mental Health Outcomes and Classification Network, 2016.

25 Australian Mental Health Outcomes and Classification Network. Health of the Nation Outcome Scales for Infants: Face Validity Study. Australian Mental Health Outcomes and Classification Network, 2016.

26 Amsterdam Public Health. COSMIN Helps you Select the Most Suitable Outcome Measurement Instruments. Amsterdam Public Health, 2018 (https://www.cos min.nl/).

27 Prinsen CAC, Mokkink LB, Bouter LM, Alonso J, Patrick DL, de Vet HCW, et al. COSMIN guideline for systematic reviews of patient-reported outcome measures. Qual Life Res 2018; 27: 1147-57.

28 Mokkink LB, Prinsen CAC, Patrick DL, Alonso J, Bouter LM, de Vet HCW, et al. Cosmin Methodology for Systematic Reviews of Patient-Reported Outcome Measures (Proms). User Manual. In Department of Epidemiology and Biostatistics. Amsterdam, The Netherlands: Amsterdam Public Health research institute, 2018.

29 Mokkink LB, Terwee CB, Patrick DL, Alonso J, Stratford PW, Knol DL, et al. The COSMIN study reached international consensus on taxonomy, terminology, and definitions of measurement properties for health-related patientreported outcomes. J Clin Epidemiol 2010; 63: 737-45.

30 Mokkink LB, de Vet HCW, Prinsen CAC, Patrick DL, Alonso J, Bouter LM, et al. COSMIN risk of bias checklist for systematic reviews of patient-reported outcome measures. Qual Life Res 2018; 27: 1171-9.

31 Australian Mental Health Outcomes and Classification Network. Health of the Nation Outcome Scales for Infants (HoNOSI) Field Trial Final Report. Australian Mental Health Outcomes and Classification Network, 2020 (https://www.amhocn.org/health-nation-outcome-scales-infants-honosi).

32 Zero to Three. PIR-GAS (Parent-Infant Relationship Global Assessment Scale) [Reprinted from: Diagnostic Classification of Mental Health and Developmental Disorders of Infancy and Early Childhood, Revised (DC:0-3R), 2005]. Zero to Three Press, 2005.

33 Greve K, Muller JM, Albers CC, Romer G, Achtergarde S. The emotional competence of mothers and the clinical quality of mother-child relationship in a preschool psychiatric population. Prax Kinderpsychol Kinderpsychiatr 2020; 69: 22-39.

34 Muller JM, Achtergarde S, Frantzmann H, Steinberg K, Skorozhenina O, Beyer T, et al. Inter-rater reliability and aspects of validity of the parent-infant relationship global assessment scale (PIR-GAS). Child Adolesc Psychiatry Ment Health 2013; 7: 17.

35 Skovgaard AM, Houmann T, Christiansen E, Olsen EM, Landorph SL, Lichtenberg $A$, et al. Can a general health surveillance between birth and 10 months identify children with mental disorder at 1(1/2) year? A case-control study nested in cohort CCC 2000. Eur Child Adolesc Psychiatry 2008; 17: 290-8.

36 Thomas JM, Clark R. Disruptive behavior in the very young child: diagnostic classification: $0-3$ guides identification of risk factors and relational interventions. Infant Ment Health J 1998; 19: 229-44.

37 Australian Association for Infant Mental Health Inc. AAIMHI Newsletter. AAIMHI 2016; 29(1) (https://www.aaimh.org.au/resources/newsletter-archive/newsletters-2011\%20to\%202015/AAIMHI-v29-1-May-2016.pdf).

38 Australian Mental Health Outcomes and Classification Network. Health of the Nation Outcome Scales for Infants (HoNOSI), 2021. (https://www.amhocn. org/publi cations/health-nation-outcome-scales-infants-honosi).

39 Burgess $\mathrm{P}$, Trauer T, Coombs T, McKay R, Pirkis J. What does 'clinical significance' mean in the context of the health of the nation outcome scales? Australas 2009; 17: 141-8.

40 IBM Corp. IBM SPSS Statistics. 24 edn. IBM, 2016.

41 StataCorp. Stata Statistical Software: Release 14. StataCorp LP, 2015. 
42 Collins NJ, Prinsen CA, Christensen R, Bartels EM, Terwee CB, Roos EM. Knee Injury and Osteoarthritis Outcome Score (KOOS): systematic review and meta-analysis of measurement properties. Osteoarthritis Cartilage 2016; 24: 1317-29.

43 Brann P, Coleman G, Luk E. Routine outcome measurement in a child and adolescent mental health service: an evaluation of HoNOSCA. The Health of the Nation Outcome Scales for Children and Adolescents. Aust N Z J Psychiatry 2001; 35: 370-6.

44 Rock D, Preston N. HoNOS: is there any point in training clinicians? J Psychiatr Ment Health Nurs 2001; 8: 405-9.
45 Coombs $\mathrm{T}$, Trauer $\mathrm{T}$, Eagar $\mathrm{K}$. Training in routine mental health outcome assessment: an evaluation of the Victorian experience. Aust Health Rev 2002; 25: 74-82.

46 Brann P, Culjak G, Kowalenko N, Dickson R, Coombs T, Sved Williams A, et al. The interrater reliability of a routine outcome measure for infants and preschoolers aged under 48 months: Health of the Nation Outcome Scales for Infants. BJPsych Open, 7(3), E85. doi:10.1192/bjo.2021.39
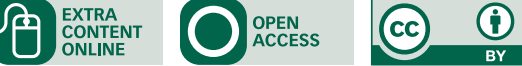